\title{
Biological and molecular characterization of silkworm strains from the Brazilian germplasm bank of Bombyx mori
}

\author{
N.C. Pereira1 ${ }^{1}$, R.E.F. Munhoz ${ }^{1}$, T.S. Bignotto ${ }^{1}$, R. Bespalhuk ${ }^{1}$, L.B. Garay ${ }^{2}$, \\ C.R.N. Saez ${ }^{1}$, V.A. Fassina ${ }^{1}$, A. Nembri ${ }^{2}$ and M.A. Fernandez ${ }^{1}$ \\ ${ }^{1}$ Departamento de Biologia Celular e Genética, \\ Universidade Estadual de Maringá, Maringá, PR, Brasil \\ ${ }^{2}$ Seda y Fibras S.R.L, Hernandarias, Alto Paraná, Paraguay \\ Corresponding author: M.A. Fernandez \\ E-mail: aparecidafernandez@gmail.com
}

Genet. Mol. Res. 12 (2): 2138-2147 (2013)

Received July 26, 2012

Accepted March 2, 2013

Published June 28, 2013

DOI http://dx.doi.org/10.4238/2013.June.28.1

\begin{abstract}
Brazil has only one public genetic pool of Bombyx mori strains, which was established in 2005 at Universidade Estadual de Maringá, Maringá, Paraná State. This genetic bank has been maintained, and the strains have been characterized using genetic and morphological tools. The quantitative and qualitative traits, directly or indirectly related to productivity, were evaluated in 14 silkworm strains. In addition to biological and productivity analyses, DNA markers related to susceptibility to the $B$. mori nucleopolyhedrovirus (BmNPV) were analyzed. BmNPV is a major cause of production loss and is a serious problem for Paraná sericulture. The silkworm strains from diverse geographic origins were found to have different characteristics, including body weight, larval stage duration, cocoon weight, and other biological traits. In terms of productivity, the raw silk percentages were almost uniform, with an overall average of $16.28 \%$. Overall, the Chinese strain C37 gave the best performance in many of the quantitative traits, and it surpassed the other strains in productivity
\end{abstract}


traits. Therefore, it can be used as one of the strains that compose the elite germplasm for silkworm breeding programs. Additionally, genetic molecular markers were efficient in discriminating between $B$. mori strains that had been identified based on their geographical origin. We found that all Japanese strains produced a 400-bp molecular marker that has been associated with susceptibility to BmNPV.

Key words: RAPD molecular genetic markers; Breeding; BmNPV; Germplasm bank

\section{INTRODUCTION}

Bombyx mori L. was described by Linnaeus in 1758 and belongs to the order Lepidoptera and the family Bombycidae. $B$. mori has been domesticated for approximately 5000 years using a practice called sericulture. The silkworm is a well-known lepidopteran, and it has been used as a model system to provide a rich repertoire of information related to genetic mutations that affect morphology, development, and behavior (Arunkumar et al., 2006). This species has been used as a source of silk production and has lost some features through many years of breeding under artificial conditions and the domestication process.

Silkworm specimens are no longer observed in nature and are totally dependent on human intervention for their survival. Genetic stocks of this species are found only in germplasm banks. Silkworm germplasm banks are important reservoirs of biodiversity and a source of alleles that can be easily retrieved for the genetic enhancement of popular strains. Accurate estimation of genetic diversity is becoming more important in the conservation of silkworm genetic resources. The use of molecular markers provides a much more accurate analysis of genetic diversity than the evaluation of morphological traits (Jingade et al., 2011). In 2006, the Universidade Estadual de Maringá (UEM) initiated the Program for Silkworm Genetic Breeding. This genetic wealth has thus been consolidated in the only public B. mori germplasm bank in Brazil.

Economic interest in this lepidopteran has promoted great advances in domestication and genetic breeding. The genetic improvement of $B$. mori is important in obtaining hybrids with increased productivity and lower susceptibility to various diseases. According to Fonseca and Fonseca (1988), a silkworm breeding program requires a survey of all the important sericulture characters related to the nature of the egg, larva, cocoon, and moth.

Many pathogens can affect $B$. mori strains, but their susceptibility to baculovirus infection is the major cause of production loss in sericulture and accounts for approximately $70 \%$ of cocoon losses (Brancalhão, 2002). One of the most important agents that cause this lethal silkworm disease is the B. mori nucleopolyhedrovirus (BmNPV). Therefore, the prediction of strain susceptibility or resistance to BmNPV is an important criterion in the evaluation of strains from the genetic bank. Yao et al. (2003) reported that random amplified polymorphic DNA (RAPD) markers could be associated with these characteristics.

Genetic and biological analyses of B. mori strains from germplasm banks are one of the most important steps in the maintenance, conservation, and use of these genetic resources (Chen, 2003). Based on the characterization of germplasm data and the identification of resistant strains, it is possible to develop commercial and experimental silkworm hybrids for industrial and scientific research (Srivastava et al., 2005). 
In our study, 14 B. mori strains maintained at the UEM Brazilian Germplasm Bank were evaluated for biological and productivity traits, as well as for molecular genetic markers, including possible susceptibility to BmNPV.

\section{MATERIAL AND METHODS}

\section{Biological and productivity analyses}

Experiments were carried out on 14 B. mori parental strains maintained at the UEM Brazilian Germplasm Bank. Biological traits related to strain characterization and production performance were evaluated; genetic analyses were also performed. The silkworm strains evaluated and their geographical origins are shown in Table 1.

\begin{tabular}{lc}
\multicolumn{1}{c}{ Table 1. Geographical origin of the 14 Bombyx mori strains from the UEM Brazilian Germplasm Bank. } \\
\hline Strain & Geographical origin \\
\hline AS3 & China \\
AS31 & China \\
C75 & China \\
C36 & China \\
C37 & China \\
E8 & Japan \\
F6 & Japan \\
JK & Japan \\
M8 & Japan \\
M11-2 & Japan \\
M18 & Japan \\
M11 & Japan \\
B82 & Japan \\
B106 & Japan \\
\hline
\end{tabular}

Silkworm larvae from each strain were reared on the same nutritional diet of mulberry leaves in rearing houses under semi-controlled temperature. The biological traits analyzed were egg shape (ES), color of the newly hatched larva (CNL), larval markings (LM), cocoon shape (CS), cocoon color (CC), pupa color (PC), pupa shape (PS), and color of the female and male moths. The 16 quantitative variables for evaluated production performance were cocoon weight $(\mathrm{CW}, \mathrm{g})$, cocoon shell weight (CSW, g), cocoon length $(\mathrm{CL}, \mathrm{mm})$, cocoon width $(\mathrm{CWd}, \mathrm{mm})$, raw silk percent $[\mathrm{RSP}=$ shell weight of 30 cocoon shells $(\mathrm{g}) / 30$ cocoon weights $(\mathrm{g}) \times 100 ; 24 \%$ was deducted from this value due to silk wiring loss], number of eggs (unit)/moth, rate of hatching (\%), total larval duration (days), duration of the 5th instar (days), larva weight on the 5th day of the 5th instar (g), silk gland pair weight of larva on the 5th day of the 5th instar (g), pupa weight (g), malformed cocoon rate $(\%)$, ambushing rate $(\%)$, cocoons per liter and pupa mortality rate $(\%)$.

The experimental delineation was completely randomized, and the data obtained from qualitative and quantitative evaluations were submitted to analysis of variance, followed by the Scott-Knott test (0.05\%) using the SISVAR statistical software.

\section{Genetic analysis}

Genomic DNA was extracted from the silkworm moth according to Monesi et al. (1998), 
with modifications. Briefly, silk moths were first frozen with liquid nitrogen and ground using a cooled mortar and pestle. The homogenate was dissolved in $750 \mu \mathrm{L}$ extraction buffer $(10 \mathrm{mM}$ Tris- $\mathrm{HCl}, \mathrm{pH} 7.5,60 \mathrm{mM} \mathrm{NaCl}, 10 \mathrm{mM}$ EDTA, $\mathrm{pH} 8.0,5 \%$ sucrose, $0.15 \mathrm{mM}$ spermine, 0.15 $\mathrm{mM}$ spermidine), centrifuged at $10,000 \mathrm{rpm}$ for $15 \mathrm{~min}$ and transferred to a new tube containing proteinase K buffer (0.2 M Tris-HCl, $\mathrm{pH} 9.0,30 \mathrm{mM}$ EDTA, $\mathrm{pH}$ 8.0, 5\% sucrose, 2\% SDS, 100 $\mu \mathrm{g} / \mathrm{mL}$ proteinase $\mathrm{K}$ ). The samples were incubated at $50^{\circ} \mathrm{C}$ for $2 \mathrm{~h}$, centrifuged at $12,000 \mathrm{rpm}$ for $15 \mathrm{~min}$ and extracted with chloroform and phenol/chloroform. The DNA-containing phase was ethanol-precipitated in the presence of $0.2 \mathrm{M} \mathrm{NaCl}$ and resuspended in TE buffer $(10 \mathrm{mM}$ Tris-HCl, $1 \mathrm{mM}$ EDTA, pH 8.0) containing $10 \mathrm{mg} / \mathrm{mL}$ RNase. The DNA was re-extracted with phenol/chloroform and ethanol-precipitated as described above and was quantified using a UV1650PC UV-visible spectrophotometer (Shimadzu) and diluted to $60 \mathrm{ng} / \mu \mathrm{L}$ for RAPD analysis.

RAPD analysis was carried out by the amplification of genomic DNA in a thermal cycler (Eppendorf) using $20 \mathrm{~mL}$ 10X Taq polymerase buffer, $200 \mathrm{mM}$ dNTPs, $1.0 \mathrm{mM} \mathrm{MgCl}_{2}$, $25 \mu \mathrm{M}$ primer, $1 \mathrm{U}$ Taq polymerase, and $60 \mathrm{ng}$ template DNA. The amplification conditions were 38 cycles at $94^{\circ} \mathrm{C}$ for $30 \mathrm{~s}$, annealing at $36^{\circ} \mathrm{C}$ for $60 \mathrm{~s}$ and extension at $72^{\circ} \mathrm{C}$ for $120 \mathrm{~s}$, followed by a final extension at $72^{\circ} \mathrm{C}$ for $10 \mathrm{~min}$.

The primers OPW-11 (5'-CTGATGCGTG-3') and OPA-18 (5'-AGGTGACCGT-3') were described by Yao et al. (2003) and were used in the analysis. PCR products of the OPW-11 primer were analyzed by electrophoresis on a $1.5 \%$ agarose gel run for $1 \mathrm{~h}$ at $100 \mathrm{~V}$; PCR products generated by the OPA-18 primer were analyzed on an $8 \%$ polyacrylamide gel run for $17 \mathrm{~h}$ at $110 \mathrm{~V}$.

RAPD analyses were conducted using the BioNumerics software (version 6.5, Applied Maths, Kortrijk, Belgium). The polymorphisms generated by the OPW-11 and OPA18 primers were used to determine the Jaccard coefficient, which was used to construct the UPGMA dendrogram.

\section{RESULTS AND DISCUSSION}

\section{Biological and productivity analyses}

The evaluation of qualitative and quantitative traits helps characterize and differentiate between different strains from the UEM Brazilian Germplasm Bank. In addition to helping to maintain the germplasm bank, these analyses are crucial in choosing the parents involved in the production of superior hybrids in breeding programs. Moreover, the biological performance of B. mori reflects maximum final silk production potential (Porto et al., 2004). Qualitative traits from 14 silkworm strains were evaluated, including ES, CNL, presence of LM, CS, CC, PC, PS, female moth color, and male moth color; the results are listed in Table 2.

ES varied according to the geographical origin of the strain; Japanese strains had elliptical-shaped eggs, whereas Chinese strains had oval-shaped eggs. Most of the eggs were small in size, except for AS3 and C75 strains. Many of the CNL were brown in color. Exceptions included the AS31, C36, C37, and JK strains, whose CNL were black. Two patterns of LM, plain and multilunar, were observed. Plain larvae did not have any markings, whereas multilunar larvae had 2 different characteristic spots. In the literature, different types of LM have been described, including zebra, speckled, quail, multistars, and others (Tazima, 1978). LM is a useful variable as it helps prevent the mixing or contamination of larvae from different strains. 
Table 2. Qualitative traits related to 14 Bombyx mori strains from the UEM Brazilian Germplasm Bank.

\begin{tabular}{llllllllll}
\hline Strains & ES & CNL & LM & CS & CC & PC & PS & FC & MC \\
\hline AS3 & Large oval & Brown & Plain & Oval & Bright white & Brown & Elliptical & Light cream & Dark cream \\
AS31 & Small oval & Black & Plain & Oval & Bright white & Brown & Elliptical & Light cream & Dark cream \\
C75 & Large oval & Brown & Plain & Oval & Bright white & Brown & Elliptical & Light cream & Dark cream \\
C36 & Small oval & Black & Plain & Oval & Bright white & Brown & Elliptical & Light cream & Dark cream \\
C37 & Small elliptical & Black & Plain & Oval & Opaque white & Brown & Elliptical & Light cream & Dark cream \\
E8 & Small elliptical & Brown & Multilunar & Elliptic & Bright white & Brown & Elliptical & Light cream & Dark cream \\
F6 & Small elliptical & Brown & Multilunar & Elliptic & Bright white & Brown & Elliptical & Light cream & Dark cream \\
JK & Small elliptical & Black & Multilunar & Elliptic & Bright white & Brown & Elliptical & Light cream & Dark cream \\
M8 & Small elliptical & Brown & Multilunar & Peanut & Bright white & Brown & Elliptical & Light cream & Dark cream \\
M11-2 & Small elliptical & Brown & Multilunar & Peanut & Opaque white & Brown & Elliptical & Light cream & Dark cream \\
M18 & Small elliptical & Brown & Multilunar & Peanut & Bright white & Brown & Elliptical & Light cream & Dark cream \\
M11 & Small elliptical & Brown & Multilunar & Peanut & Bright white & Brown & Elliptical & Light cream & Dark cream \\
B82 & Small elliptical & Brown & Multilunar & Peanut & Bright white & Brown & Elliptical & Light cream & Dark cream \\
B106 & Small elliptical & Brown & Multilunar & Peanut & Opaque white & Brown & Elliptical & Light cream & Dark cream \\
\hline
\end{tabular}

$\mathrm{ES}=$ eggs shape $; \mathrm{CNL}=$ color of the newly hatched larva $\mathrm{LM}=$ larval marking; $\mathrm{CS}=$ cocoon shape $\mathrm{CC}=$ cocoon color; $\mathrm{PC}=$ pupa color; $\mathrm{PS}=$ pupa shape; $\mathrm{FC}=$ female moth color; $\mathrm{MC}=$ male moth color.

CS can be either elliptical or oval and can also exhibit variations in the intensity of constriction at the center of the cocoon (Bojan et al., 2007). Although the intensity of constriction varied between strains, the Chinese strains produced oval cocoons and Japanese strains produced elliptical or peanut cocoons in this study. CS is an extremely relevant variable in commercialization, since automated wiring admits only elliptical cocoons into the machines. In general, silkworm CC can vary greatly. There are descriptions of green, pink, and blue cocoons (Basavaraja et al., 2005). However, the strains evaluated in the present study did not show any variation related to color. All of the strains produced white cocoons that varied in brightness and opacity as indicated in Table 2.

Important strain features such as PC, PS and moth color were uniform (Table 2), demonstrating that these variables were not indicative of the qualitative distinction between the strains analyzed. This homogeneity hampers pupa and moth morphological characterization; therefore, researchers should take care when performing crosses between individuals for strain maintenance or breeding.

The quantitative variables analyzed, including CW, CSW, CL, CWd, and RSP, are shown in Table 3. CW and CL varied greatly, with values ranging from 0.73 to $1.66 \mathrm{~g}$ for $\mathrm{CW}$ and from 28.5 to $35.2 \mathrm{~mm}$ for CL. In general, Chinese strains performed the best regarding $\mathrm{CW}$, except for the AS31 strain. In contrast, most Chinese strains demonstrated low CL values, with the $\mathrm{C} 37$ strain being an exception. CSW variations were observed for the C37 and M11 strains of Chinese and Japanese origin, respectively (Table 3 ). In contrast, only minor variation was observed for cocoon width, with values ranging from $13.14 \mathrm{~mm}$ for the M8 strain to $20.85 \mathrm{~mm}$ for the C37 strain.

The RSP is a more uniform trait among the strains analyzed, with an overall average of $16.28 \%$. This value was lower than the $18.21 \%$ reported by Zanatta et al. (2009) in a study of other silkworm strains of the same UEM Brazilian Germplasm Bank. On the other hand, Porto et al. (2004) observed an average RSP of $16.37 \%$, which is closer to that observed in the present study. However, a lower value (14.99\%) than that observed in this study was reported by Kumaresan (2007). Other strains from a Pakistani germplasm bank (Hussain et al., 2010) and a polyvoltine germplasm bank (Rao et al., 2006) also revealed lower RSP values of 11.6 
and $11.1 \%$, respectively. Overall, the $\mathrm{C} 37$ strain demonstrated the best performance in most of the quantitative variables analyzed (Table 3 ) and differed from other strains in terms of productivity traits.

Table 3. Mean values of quantitative traits for 14 strains of Bombyx mori from the UEM Brazilian Germplasm Bank.

\begin{tabular}{|c|c|c|c|c|c|}
\hline Strain & CW (g) & CSW (g) & $\mathrm{CL}(\mathrm{mm})$ & $\mathrm{CWd}(\mathrm{mm})$ & RSP \\
\hline AS3 & $1.38^{\mathrm{c}}$ & $0.32^{\mathrm{b}}$ & $29.00^{\mathrm{f}}$ & $20.07^{\mathrm{a}}$ & $16.80^{\mathrm{a}}$ \\
\hline AS31 & $0.89^{\mathrm{e}}$ & $0.17^{\mathrm{e}}$ & $29.23^{\mathrm{e}}$ & $19.13^{\mathrm{a}}$ & $14.60^{\mathrm{b}}$ \\
\hline $\mathrm{C} 75$ & $1.36^{\mathrm{c}}$ & $0.25^{\mathrm{c}}$ & $29.61^{\mathrm{e}}$ & $19.65^{\mathrm{a}}$ & $14.41^{\mathrm{b}}$ \\
\hline $\mathrm{C} 36$ & $1.38^{\mathrm{c}}$ & $0.31^{\mathrm{b}}$ & $28.50^{\mathrm{f}}$ & $19.45^{\mathrm{a}}$ & $17.20^{\mathrm{a}}$ \\
\hline $\mathrm{C} 37$ & $1.66^{\mathrm{a}}$ & $0.39^{\mathrm{a}}$ & $32.52^{\mathrm{b}}$ & $20.85^{\mathrm{a}}$ & $18.01^{\mathrm{a}}$ \\
\hline E8 & $0.73^{f}$ & $0.14^{\mathrm{e}}$ & $29.23^{\mathrm{e}}$ & $15.41^{\mathrm{b}}$ & $14.61^{\mathrm{b}}$ \\
\hline F6 & $1.24^{\mathrm{d}}$ & $0.29^{\mathrm{b}}$ & $32.17^{\mathrm{b}}$ & $19.25^{\mathrm{a}}$ & $17.81^{\mathrm{a}}$ \\
\hline JK & $1.18^{\mathrm{d}}$ & $0.25^{\mathrm{c}}$ & $30.48^{\mathrm{d}}$ & $16.76^{\mathrm{b}}$ & $14.90^{\mathrm{b}}$ \\
\hline M8 & $1.19^{d}$ & $0.23^{\mathrm{c}}$ & $29.63^{e}$ & $13.14^{\mathrm{b}}$ & $15.36^{\mathrm{b}}$ \\
\hline M11-2 & $1.40^{\mathrm{c}}$ & $0.31^{\mathrm{b}}$ & $31.05^{\mathrm{d}}$ & $15.18^{\mathrm{b}}$ & $17.24^{\mathrm{a}}$ \\
\hline M18 & $1.27^{\mathrm{d}}$ & $0.24^{\mathrm{c}}$ & $31.32^{\mathrm{c}}$ & $13.71^{\mathrm{b}}$ & $14.47^{\mathrm{b}}$ \\
\hline M11 & $1.58^{\mathrm{b}}$ & $0.36^{\mathrm{a}}$ & $31.79^{c}$ & $16.52^{\mathrm{b}}$ & $17.61^{\mathrm{a}}$ \\
\hline B82 & $0.85^{\mathrm{e}}$ & $0.20^{\mathrm{d}}$ & $35.20^{\mathrm{a}}$ & $17.23^{\mathrm{b}}$ & $18.41^{\mathrm{a}}$ \\
\hline B106 & $1.38^{\mathrm{c}}$ & $0.30^{\mathrm{b}}$ & $30.69^{d}$ & $14.45^{\mathrm{b}}$ & $16.51^{\mathrm{a}}$ \\
\hline Average & 1.25 & 0.27 & 30.74 & 17.20 & 16.28 \\
\hline CV $(\%)$ & 3.90 & 7.88 & 1.22 & 11.33 & 7.80 \\
\hline
\end{tabular}

Means followed by distinct letters in the columns are different by the Scott-Knott test $(\mathrm{P}<0.05)$. CW $=$ cocoon weight; $\mathrm{CSW}=$ cocoon shell weight; $\mathrm{CL}=$ cocoon length; $\mathrm{CWd}=$ cocoon width $\mathrm{RSP}=$ raw silk percent; $\mathrm{CV}=$ coefficient of variation.

For a more complete characterization of the 14 strains, 11 additional traits were evaluated, and the results are shown in Table 4. In this analysis, a large variation was observed in the number of eggs per laying. The best performance was observed with the JK strain with an average of 644 eggs per laying, and the worst performance was observed with the B106 strain with an average of 270 eggs per laying. Overall, 9 strains laid more eggs than the average value of 409.79 reported by Porto et al. (2004).

\section{Table 4. Quantitative traits related to 14 Bombyx mori strains from the UEM Brazilian Germplasm Bank.}

\begin{tabular}{|c|c|c|c|c|c|c|c|c|c|c|c|}
\hline Strains & Egg & Hat & Cycle & ILD & LW & SGW & PW & $\mathrm{MC}$ & PR & $\mathrm{C} / \mathrm{L}$ & MR \\
\hline AS3 & 615 & 70.8 & 30.0 & 8 & 3.38 & 4.7 & 1.25 & 30.5 & 65 & 79 & 5.5 \\
\hline AS31 & 394 & 84.5 & 30.0 & 8 & 2.99 & 3.7 & 1.07 & 26.2 & 65 & 96 & 0 \\
\hline C75 & 585 & 65.0 & 30.0 & 8 & 3.07 & 4.3 & 1.24 & 26.3 & 65 & 77 & 13.3 \\
\hline C36 & 496 & 84.8 & 30.0 & 8 & 3.06 & 3.9 & 1.22 & 25.9 & 65 & 91 & 14.4 \\
\hline C37 & 442 & 69.9 & 29.5 & 8 & 3.44 & 4.8 & 1.21 & 15.3 & 65 & 66 & 0 \\
\hline E8 & 568 & 81.5 & 30.0 & 8 & 2.42 & 3.7 & 0.94 & 21.6 & 65 & 120 & 18.3 \\
\hline F6 & 536 & 75.0 & 28.5 & 8 & 2.78 & 4.0 & 1.05 & 13.4 & 65 & 96 & 3.3 \\
\hline JK & 644 & $*$ & 30.0 & 8 & 2.44 & 2.8 & 0.88 & $* *$ & 65 & $* *$ & 5.5 \\
\hline M8 & 289 & $*$ & 27.0 & 8 & 2.94 & 4.5 & 0.95 & 13.4 & 80 & 160 & 0 \\
\hline M11-2 & 323 & $*$ & 27.0 & 8 & 2.82 & 4.2 & 1.21 & 10.0 & 80 & 126 & 4.4 \\
\hline M18 & 313 & $*$ & 27.0 & 8 & 2.55 & 3.0 & 1.11 & 8.5 & 80 & 129 & 14.4 \\
\hline M11 & 439 & $*$ & 27.0 & 8 & 3.21 & 5.2 & 1.14 & 9.3 & 80 & 86 & 5.5 \\
\hline B82 & 554 & 81.9 & 31.0 & 8 & 2.93 & 3.7 & 1.45 & 69.0 & 75 & 67 & 11.1 \\
\hline B106 & 270 & $*$ & 27.0 & 8 & 2.93 & 4.4 & 1.12 & 8.0 & 80 & 95 & 0 \\
\hline
\end{tabular}

Egg = number of eggs (unit); Hat = hatchability rate (\%); Cycle = larval cycle (days); ILD = 5th-instar larval length (days); LW = larval weight on the 5th day of 5th instar (g); SGW = silk gland weight on the 5th day of 5th instar (g); $\mathrm{PW}=$ pupa weight (g); $\mathrm{MC}=$ malformed cocoons $(\%) ; \mathrm{PR}=$ pupation rate $(\%) ; \mathrm{C} / \mathrm{L}=$ cocoons per liter (unit); $\mathrm{MR}=$ mortality rate $(\%) .{ }^{*}$ Values below $10 \% ; * *$ lost portion. 
Larva cycle and 5th instar length were fairly uniform in all 14 strains, in contrast to the results observed by Kumaresan et al. (2007). In this study, a variation in the 5th instar length of up to 3 days was observed. This behavior indicates that the 14 strains maintained at the UEM Brasilian Germplasm Bank are rather homogeneous, which allows crossing and breeding between different strains at the same time. These variables are directly influenced by environmental factors, such as the amount of available food, temperature, light, and moisture. As the variables analyzed were uniform across all strains, their management must be similar.

The highest value for larva weight on the 5th day of the 5th instar was observed with the Chinese strain C37, whereas the Japanese strain M11 exhibited the highest value for silk gland weight on the 5th day of the 5th instar. Values for pupa weight were relatively uniform, but the B 82 and JK strains yielded the best $(1.45 \mathrm{~g})$ and worst $(0.88 \mathrm{~g})$ performances, respectively, for this characteristic. The malformed cocoon rate varied greatly, with strain B82 yielding the highest value (69\%) and strain B106 yielding the lowest (8\%).

For the characteristic pupation rate, which is a very important trait for producers, the best results were observed with the Japanese strains M8, M11-2, M18, M11, B82, and B106 (over 75\%). In contrast, all Chinese strains achieved a rate of $65 \%$ for this parameter. The cocoons per liter (how many cocoons fit into a one-liter container) values varied greatly from 66 to 160. The Japanese strain C37 yielded the lowest number of cocoons in a liter (66), indicating that their cocoons are larger compared to the other strains. This result was expected as this strain produced the biggest cocoons (Table 3 ).

Strains AS31, C37, M8, and B106 demonstrated no mortality throughout their life cycle, resulting in a mortality rate of zero (Table 4). These are promising strains for future candidates to constitute the elite germplasm of B. mori. However, the E8 strain demonstrated the highest value for this variable.

The most important characteristics related to silkworm production performance are CW, CSW, and RSP. RSP is a measurement that includes both CW and CSW, among other factors, and it defines the final value of the cocoon (Zanatta et al., 2009). CW, CSW and RSP represent important economic silkworm traits. Additionally, they are highly heritable, are affected by additive gene action, and allow a better response to selection (Petkov and Nguyenvan, 1987).

Zanatta et al. (2009) evaluated other strains in the same germplasm bank. Although some values were similar to our results, they observed higher CW values for the HA-A and HA-B strains, 2 Japanese strains that produce long peanut cocoons, higher CSW values for the HA-A, HA-B, C24-A, and M12-B strains and a higher CL value for the HA-A strain. In another study, Porto et al. (2004) analyzed several biological and productivity characteristics of 8 B. mori strains of Chinese and Japanese origin. The overall average number of eggs per laying was smaller (409.79) than that observed for our strains (462). However, some strains analyzed by Porto et al. (2004) demonstrated a higher mortality rate, including the B101, B102, C201, C202, and C208 strains. Regarding productivity traits, our C37 and M11 strains showed higher CSW values ( 0.39 and $0.36 \mathrm{~g}$, respectively) when compared to the strains evaluated by Porto et al. (2004). The highest CSW value observed by these authors was $0.31 \mathrm{~g}$ for the Chinese strain C202. However, the CL and CWd values were nearly identical.

In a study performed by Rao et al. (2006) using silkworm strains from a polyvoltine germplasm bank, a mean value of 461 eggs per laying was found, which is closer to the value observed in our study. Nevertheless, pupation rates of the multi- and polyvoltine strains reached a value greater than $86 \%$, which is higher than that observed in our study $(80 \%)$. The 
mean $\mathrm{CW}$ value for both multi- and polyvoltine strains was $1.30 \mathrm{~g}$, which is higher than the value detected in our strains (1.25 g). Hussain et al. (2010) conducted a study with 11 silkworm strains from a breeding and cocoon production program in Pakistan. They found a mean value of 480 eggs per laying, a pupation rate of $87.08 \%$, a mortality rate of $5.6 \%$, CW of 1.47 $\mathrm{g}$, and CSW of $0.30 \mathrm{~g}$.

The silkworm varieties chosen for the present study revealed marked differences in diverse characteristics, including geographic origin, body weight, larval span, cocoon weight, and other biological traits. We also examined the genetic divergence among $B$. mori strains.

\section{Genetic analysis}

RAPD markers were used to analyze genetic diversity among strains maintained at the UEM Brazilian Germplasm Bank. The RAPD technique was utilized to verify the genetic polymorphism, as well as susceptibility to BmNPV, using primers OPW-11 (5'-CTGATGCGTG3') and OPA-18 (5'-AGGTGACCGT-3').

The RAPD fragments obtained with the OPW-11 primer can be visualized in Figure 1. Our results were similar to those obtained by Yao et al. (2003) using the same primer. Of the strains analyzed, all those of Japanese origin produced a molecular marker of $400 \mathrm{bp}$, which could be indicative of susceptibility to BmNPV. In a study conducted by Zanatta (2006), this molecular marker primer (OPW-11 $\left.1_{400}\right)$ was also observed in all Japanese strains analyzed. The amplification pattern of molecular marker OPW- $11_{400}$ confirms the observation that Japanese strains, which are known to be better silk producers than Chinese strains, are less resistant to diseases and to multiple field factors (Fernandez et al., 2005; Zanatta, 2006).

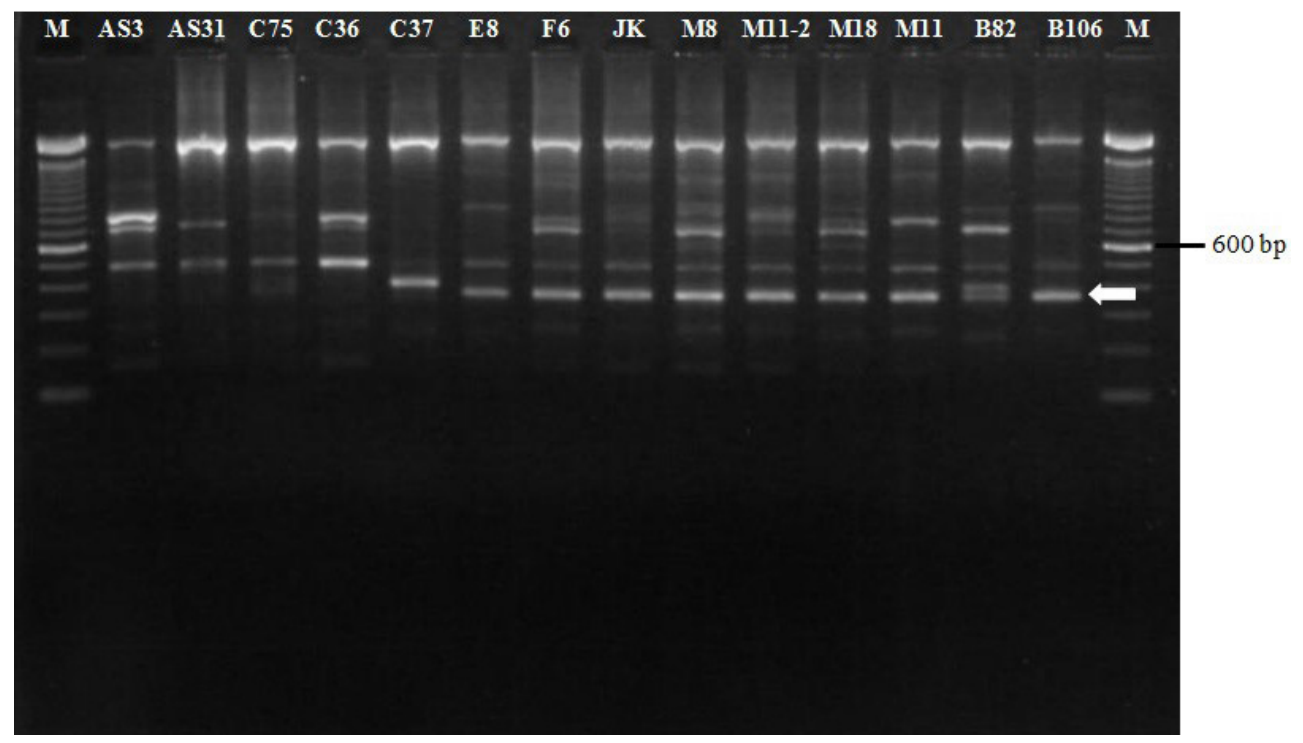

Figure 1. Random amplified polymorphic DNA profile of 14 Bombyx mori strains from the UEM Brazilian Germplasm Bank. DNA was amplified with the OPW-11 primer. Lane $M=100$-bp molecular weight marker (Invitrogen). The arrow indicates a 400-bp band, which is found in the genotype of species sensitive to BmNPV (described by Yao et al., 2003). 

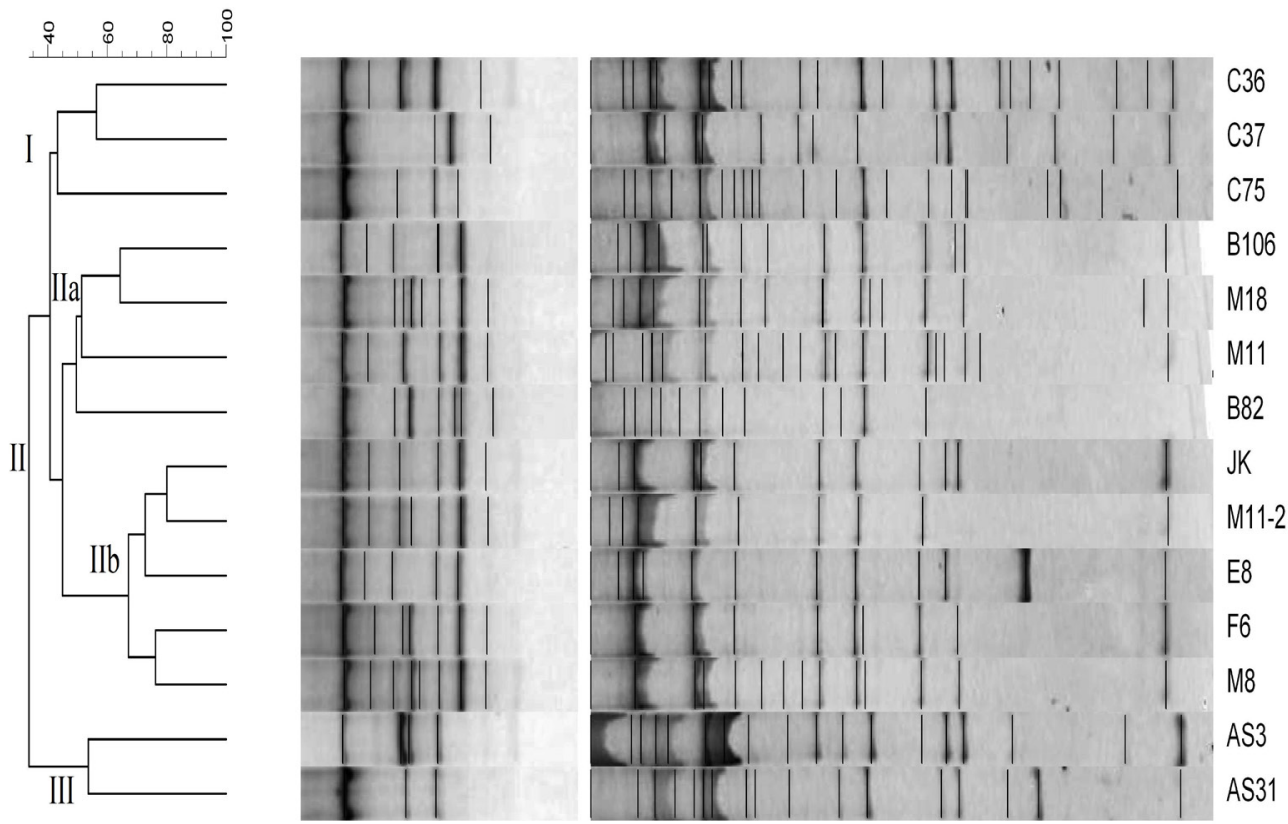

Figure 2. Cluster analysis based on 14 Bombyx mori strains from UEM Brazilian Germplasm Bank data. The analysis was carried out using the Jaccard coefficient and UPGMA grouping.

Individuals were grouped into 3 major clusters that were separated according to their geographical origin. Group I included the Chinese strains C36, C37, and C75. Group II contained nine Japanese strains clearly divided into 2 subgroups; subgroup IIa contained the B106, M18, M11, and B82 strains and subgroup IIb contained the JK, M11-2, E8, F6, and M8 strains. The Chinese strains AS3 and AS31 were separated from the other strains to comprise group III.

$B$. mori has undergone an intense process of domestication with frequent consanguineous crosses. As a result, the silkworm has accumulated a high level of homozygosity and, consequently, a low level of polymorphisms. This is probably because all cultivated silkworm strains originated from a common ancestor with a long history of inbreeding under consistently strong selective conditions for strain maintenance and improvement (Miao et al., 2005). Nevertheless, RAPD analysis has proven to be an efficient technique to detect variability in different $B$. mori strains. These polymorphisms are useful in the genetic analysis of and discrimination between silkworm strains. Furthermore, RAPD molecular markers can be used to identify strains that are susceptible to the baculovirus BmNPV.

\section{ACKNOWLEDGMENTS}

Research supported by CAPES, CNPq, FINEP/Fundação Araucária and Secretaria de Estado da Ciência, Tecnologia e Ensino Superior - FUNDO PARANÁ. We gratefully acknowledge all the staff members of Laboratório de Organização Funtional do Núcleo (LORF) for their assistance with the measurements and the COMCAP facilities. 


\section{REFERENCES}

Arunkumar KP, Metta M and Nagaraju J (2006). Molecular phylogeny of silkmoths reveals the origin of domesticated silkmoth, Bombyx mori from Chinese Bombyx mandarina and paternal inheritance of Antheraea proylei mitochondrial DNA. Mol. Phylogenet. Evol. 40: 419-427.

Basavaraja HK, Aswath SK, Suresh Kumar N, Mal Reddy N, et al (2005). Silkworm Breeding and Genetics. Central Silk Board, Bangalore.

Bojan C, Marghitas LA, Dezmirean D, Orsolya T, et al. (2007). Qualitative characters study for silkworm hybrids. Bull. USAMV-CN 63/64: 219-223.

Brancalhão RMC (2002). Vírus entomopatogênicos no bicho da seda: taxonomia e citopatologia causada por Nucleopolyhedrovirus em células de Bombyx mori. Biotecnol. Cienc. Desenvol. 4: 54-58.

Chen K, Yao Q, Wang Y and Cheng J (2003). Genetic basis of screening of molecular markers for nuclear polyhedrosis virus resistance in Bombyx mori L. Int. J. Indust. Entomol. 7: 5-10.

Chen Y (2003). Conservation Status of Silkworm Germplasm Resources in China. Food and Agriculture Organization of the United Nations (FAO). Available at [http://www.fao.org/docrep/005/AD108E/ad108e01.htm\#TopOfPage]. Accessed February 24, 2012.

Fernandez MA, Ciferri RR, Patussi EV, Pereira MF, et al. (2005). A utilização da biotecnologia na sericicultura brasileira. Biotecnol. Cienc. Desenvol. 35: 52-57.

Fonseca AS and Fonseca TC (1988). Cultura da Amoreira e Criação do Bicho-da-Seda. Nobel, São Paulo.

Hussain M, Khan SA and Aslam M (2010). Evaluation of genetic potential of inbred pure lines of silkworm for breeding and cocoon production in Pakistan. Afr. J. Food Sci. 4: 300-302.

Jia-Ping X, Ke-Ping C, Ming-Hui L, Qin Y, et al. (2008). Identification and characterization of Bms3a in Bombyx mori L. Afr. J. Biotechnol. 7: 3424-3430.

Jingade AH, Vijayan K, Somasundaram P, Srivasababu GK, et al. (2011). A review of the implications of heterozygosity and inbreeding on germplasm biodiversity and its conservation in the silkworm, Bombyx mori. J. Insect Sci. 11: 8.

Kumaresan P, Sinha RK and Urs SR (2007). An analysis of genetic variation and divergence in Indian tropical polyvoltine silkworm (Bombyx mori L.) genotypes. Caspian J. Environ. Sci. 5: 11-17.

Miao XX, Xub SJ, Li MH, Li MW, et al. (2005). Simple sequence repeat-based consensus linkage map of Bombyx mori. Proc. Natl. Acad. Sci. U. S. A. 102: 16303-16308.

Monesi N, Jacobs-Lorena M and Paçó-Larson ML (1998). The DNA puff gene BhC4-1 of Bradysia hygida is specifically transcribed in early prepupal salivary glands of Drosophila melanogaster. Chromosoma 107: 559-569.

Petkov N and Nguyenvan L (1987). Breeding genetic studies on some lines of the silkworm, Bombyx mori L. Genetika-iSelektsiya 20: 384-354.

Porto AJ, Okamoto F, Cunha EA and Otsuk IP (2004). Caracterização de oito raças do bicho-da-seda (Bombyx mori L.). Cienc. Rural 34: 259-264.

Rao CG, Seshagiri SV, Ramesh C, Ibrahim BK, et al. (2006). Evaluation of genetic potential of the polyvoltine silkworm (Bombyx mori L.) germplasm and identification of parents for breeding programme. J. Zhejiang Univ. Sci. B 7: 215220.

Srivastava DP, Yu EJ, Kennedy K, Chatwin H, et al. (2005). Rapid, nongenomic responses to ecdysteroids and catecholamines mediated by a novel Drosophila G-protein-coupled receptor. J. Neurosci. 25: 6145-6155.

Tazima Y (1978). The Silkworm: An Important Laboratory Tool. Kodansha Scientific Books, Tamil Nadu.

Yao Q, Lim MW, Wang Y, Wang WB, et al. (2003). Screening of molecular markers for NPV resistance in Bombyx mori L. (Lep., Bombycidae). J. Appl. Entomol. 127: 134-136.

Zanatta D (2006). Identificação de Marcadores RAPD para Polimorfismo, Resistência e Suscetibilidade em Linhagens de Bombyx mori. Master's thesis, Universidade Estadual Maringá, Maringá.

Zanatta D, Bravo JP, Barbosa JF, Munhoz REF, et al. (2009). Evaluation of economically important traits from sixteen parental strains of the silkworm Bombyx mori L. (Lepidoptera: Bombycidae). Neotrop. Entomol. 38: 327-331. 